\title{
Progress of comprehensive rehabilitation of patients with spinal cord lesions in Germany 1962-1990
}

\section{F-W Meinecke MD}

Krummwisch 6, D-2057 Reinbek, Germany.

(The contents of this paper is restricted to Germany before union).

\section{Statistics}

In 1962 there were 10 spinal cord injury (SCI) centres in Germany and in 1990 there were 17. Capacity in 1962 was approximately 350 beds and in 1990 approximately 800. Incidence of SCI in 1962 was 10 cases per million population per year and in 1990 19 cases per million. Precise statistics available from 1977 are: recent admission approximately 14,000 patients; readmissions approximately 26,000 ; and outpatiens approximately 44,000 . Statistics show increasing numbers from 1980 to 1989: recent admission (traumatic SCI) $42 \%$; non traumatic admissions $15 \%$; readmissions $139 \%$; outpatients $110 \%$; and bed capacity $34 \%$.

\section{Organisation}

In 1976 a bed procurement service for recent cases was created to permit physicians to decide on the transfer of a patient to a special unit. Since that time the heads of the units have created a special study group to collect data regularly, exchange experiences and to act as an advisory board. ${ }^{1} \mathrm{~A}$ network of helicopters for transportation covers the entire Republic. The goal is comprehensive rehabilitation from the very beginning up to discharge, within one centre and under one roof. A special contribution, originally published in 1972 and subsequently updated, deals with construction, room allocation, staff and geographical distribution of SCI centres. ${ }^{2}$

\section{Diagnosis:}

In addition to the standard $\mathrm{x}$-ray assessment, CT and if necessary NMR are used. Urodynamics has also been introduced.

\section{Therapy}

More than $50 \%$ of traumatic cases belong to the polytrauma group, in particular those with head and chest injuries. Intensive care is provided in all centres. Special facilities for long term or for lifetime artificial respiration are available in Bad Wildungen.

Spondylodesis by the use of GruccaWeiss-springs was begun by Bötel in $1977 .^{3}$ At the present time spinal surgery is available in all of the centres. The aim is realignment and stabilisation of the spine over a short distance after decompression. A special 'wirbelsäulen-fixateur' has been developed by Kluger. ${ }^{4}$ Stabilisation facilitates nursing and shortens confinement in bed. An increase in neurological recovery has not been proven up to now. Conservative treatment of the injured spine is still in use for patients with stable fractures or if surgery is not possible. Since 1962 internal fixation is the method of choice for fractures of the legs or arms in both recent and long standing patients. ${ }^{5}$

Greatest progress has been made in urology. Three centres have special urological departments. The results of urodynamic studies decide the therapy. The goal is compensated bladder function gained by individual therapeutic measures, with good results in $90 \%$ of patients. ${ }^{6}$ Intermittent catherisation or suprapubic drainage are in use in the early stage. According to the urodynamic findings in the long term, different treatment are applied: medication for detrusor suppression; sphincterotomy for detrusor-sphincter-dyssynergia; self catherisation if there is absent detrusor activity. In women with an aggressive hyperreflexive bladder, sacral anterior root stimulation with or without deafferentation ${ }^{7}$ may be indicated. Bladder enlargement by surgery is reserved for a small group of patients. Finally, an alloplastic sphincter may be indicated to treat stress incontinence.

Erectile dysfunction can be treated by intracavernous injection with papaverine, or by the application of a penile prosthesis. Fertility may be obtained by vibrostimulation, in some cases by physiostigmin sc, which is less dangerous than intrathecal 
prostigmin and in others by rectal electrostimulation. The sperm is of poor quality. Desired pregnancy was achieved in $48 \%$ of patients.

Severe spasticity can be treated by intrathecal baclofen with good results. In less severe cases good results are obtained by electrostimulation. Alcohol neural block and phenolisation have been given up.

Prevention of pressure sores is achieved by regular turning and the use of different kinds of mattresses or the use of special beds. Treatment may be conservative. Surgical interventions using muscle or musculocutaneous flap transplantation are the methods of choice. Modern techniques require great experience, excellent nursing and qualified physiotherapists.

Functional electrostimulation (FES) attempts to achieve some motor function in the paralysed upper or lower limbs. Up to now the results obtainable in ADL are not very encouraging. The techniques and equipment require further research.

Early attempts have been made with electrophrenic stimulation for high level tetraplegics. ${ }^{9}$ Techniques and apparatus according to Glenn ${ }^{10}$ and to Thoma ${ }^{11}$ are in use. Some of these patients have been discharged home, independent of the respirator. The entire treatment still raises medical, technical and psychological problems necessitating further investigation.

Social workers and psychologists are per- manent members of the teams in almost all of the centres.

The quality and variety of technical aids have greatly improved, as have special techniques of treatment concerning physiotherapy and occupational therapy.

\section{Special associations}

In addition to the above mentioned bed procurement service, a special study group was founded in 1985, the 'German Speaking Medical Society of Paraplegia' (DMGP) open to everbody involved in the treatment of patients with spinal cord lesions. The 'Community for Promotion of the Paralysed in Germany' is a relief organisation (self help) for paralysed people and able bodied people of any kind, including donors, dealing with all of the problems arising from spinal lesions: medical, psychological, social, legal etc. The 'German Wheelchair Sports Organisation' (DRS), the central organisation for wheelchair sports clubs from all over Germany, was also founded.

In summary, there has been striking progress in the entire field of paraplegia in the past 30 years, but it is not completely satisfactory. In the future it is necessary to appreciate all of the problems, to pay attention to technical developments, to promote research, and to solve the remain: ing questions in close cooperation with all concerned.

\section{References}

1 Meinecke F-W (1979) Two years of bed procurement for patients with spinal cord lesions. Paraplegia 17: 62-72.

2 Hauptverband der gewerblichen Berufsgenossenschaften e.V. (1991) Zur Neuordnung der Behandlungszentren für Querschittgelähmte in der Bundesrepublik Deutschland für Neubauten. 3. Aufl. St. Augustin.

3 Bötel U (1979) Stabilisierung und Früh-mobilisation bei Verrenkungs-brüchen der Rumpfwirbelsäule mit der Weiss-Feder. Unfallheilk 82: 108-113.

4 Kluger P (1989) Das Fixateurprinzip an der Rumpfwirbelsäule. In: Stuhler, Th, ed. Fixateur Externe. Springer, Berlin-Heidelberg: 36.

5 Meinecke F-W, Rehn J, Leitz G (1967) Conservative and Operative Treatment of Fractures of the Limbs in Paraplegia (1967) Proceedings of the sixteenth annual conference of the Veterans Administration, Washington: 77-91.

6 Stöhrer M (1990) Alterations in the urinary tract after spinal cord injury. 1990: World J Urol 7: 205-211.

7 Sauerwein D, Ingunza W, Madersbacher H, Polker CE, Brindley GS, Columbel P, Teddy P (1990) Extradural implantation of sacral anterior root stimulators. J Neurol Neurosurg Psychiatry 53: 681-684.

8 Löchner-Ernst D (1990) Zur Fertilität Querschnittge-lähmter Männer. In: Meinecke, F-W, ed. Querschnittlähmungen. Springer, Berlin-Heidelberg: 172.

9 Gerner H-J (1990) Elektrostimulation des Zwerchfells. In: Meinecke, F-W, ed. Querschnittlähmungen. Springer, Berlin-Heidelberg: 222

10 Glenn WWL, Hogan JF, Phelps ML (1980) Ventilatory support of the quadriplegic patient with respiratory paralysis by diaphragm. Surg Clin N Am 60 (5): 1055-1078.

11 Thoma H, Gerner HJ, Holle J et al (1987) The phrenic pacemaker. Substitution of paralyzed function in tetraplegia ASAIO 10 (3): 472-479. 